\title{
A Simple Semi-Empirical Model for the Estimation of Photosynthetically Active Radiation from Satellite Data in the Tropics
}

\author{
S. Janjai, A. Sripradit, R. Wattan, S. Buntoung, S. Pattarapanitchai, and I. Masiri \\ Solar Energy Research Laboratory, Department of Physics, Faculty of Science, Silpakorn University, Nakhon Pathom 73000, Thailand \\ Correspondence should be addressed to S. Janjai; serm@su.ac.th
}

Received 6 September 2013; Revised 30 November 2013; Accepted 30 November 2013

Academic Editor: Niyaz Mohammad Mahmoodi

Copyright (C) 2013 S. Janjai et al. This is an open access article distributed under the Creative Commons Attribution License, which permits unrestricted use, distribution, and reproduction in any medium, provided the original work is properly cited.

\begin{abstract}
This paper presents a simple semi-empirical model for estimating global photosynthetically active radiation (PAR) under all sky conditions. The model expresses PAR as a function of cloud index, aerosol optical depth, total ozone column, solar zenith angle, and air mass. The formulation of the model was based on a four-year period (2008-2011) of PAR data obtained from the measurements at four solar monitoring stations in a tropical environment of Thailand. These are Chiang Mai $\left(18.78^{\circ} \mathrm{N}, 98.98^{\circ} \mathrm{E}\right)$, Ubon Ratchathani $\left(15.25^{\circ} \mathrm{N}, 104.87^{\circ} \mathrm{E}\right)$, Nakhon Pathom $\left(13.82^{\circ} \mathrm{N}, 100.04^{\circ} \mathrm{E}\right)$, and Songkhla $\left(7.20^{\circ} \mathrm{N}, 100.60^{\circ} \mathrm{E}\right)$. The cloud index was derived from MTSAT-1R satellite, whereas the aerosol optical depth was obtained from MODIS/Terra satellite. For the total ozone column, it was retrieved from OMI/Aura satellite. The model was validated against independent data set from the four stations. It was found that hourly PAR estimated from the proposed model and that obtained from the measurements were in reasonable agreement, with the root mean square difference (RMSD) and mean bias difference (MBD) of $14.3 \%$ and $-5.8 \%$, respectively. In addition, for the case of monthly average hourly PAR, RMSD and MBD were reduced to $11.1 \%$ and $-5.1 \%$, respectively.
\end{abstract}

\section{Introduction}

Photosynthetically active radiation (PAR) is part of the solar radiation spectrum from 400 to $700 \mathrm{~nm}$. The incident PAR at the earth's surface is of importance for modeling ecosystems and climate change studies [1-4]. PAR data are also needed for accurate modeling of biomass productivities for renewable energy applications.

Although PAR can be measured by quantum PAR sensors, the number of measurement sites in most areas of the world is scarce. Consequently, PAR data from measurements are not sufficient for the demand of PAR users. To overcome this problem, PAR data need to be obtained from modeling approaches. One of these approaches is to use a ratio of PAR to broadband solar radiation to estimate PAR from more widely measured broadband radiation. Many authors have proposed the values of this ratio using PAR and broadband radiation data from different parts of the world [5-7]. Some authors presented the ratio as functions of the position of the sun and meteorological data [8-12]. Another approach is to derive
PAR from data of polar orbiting satellites [13-17] or stationary satellites such as GOES, METEOSAT, and MTSAT [18-21]. This approach is usually based on physical relation between PAR and other meteorological parameters.

The use of PAR-to-global radiation ratio has an advantage in terms of the simplicity, but it can be effectively used only for the locations where broadband solar radiation data are available. In addition, it usually lacks the generality. By contrast, the satellite physical approach is advantageous for its generality and better spatial coverage. However, it is relatively complicated and requires a lot of input data which are sometimes not available. As a compromise, we propose a new approach to estimate PAR from satellite data by using a simple semi-empirical model. The study area is focused on a tropical environment of Thailand. This environment is characterized by high humidity and high level of PAR throughout the year. Global PAR measured at four sites in Thailand and the corresponding cloud index, aerosol optical depth, and total ozone column obtained from satellites were also used for the development of the model. 


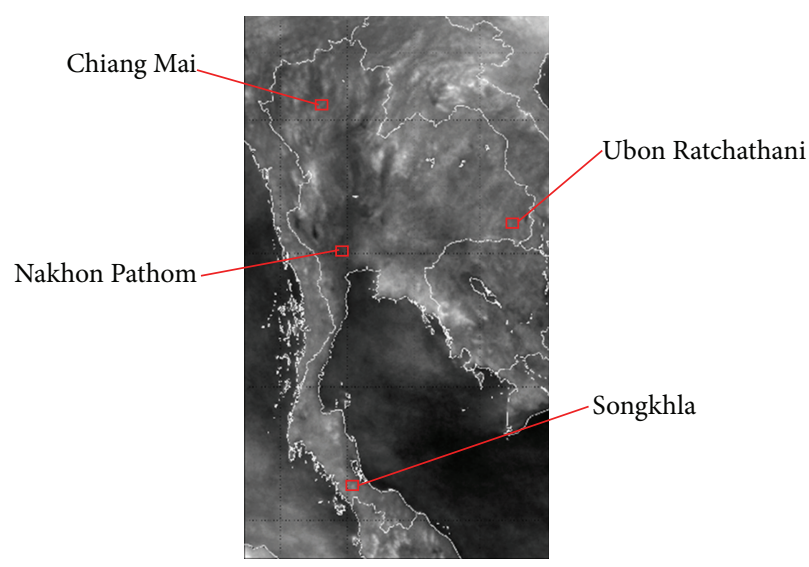

FIGURE 1: A rectified image and the positions of the target ground-based stations.

\section{Satellite Data and Ground-Based Measurements}

2.1. Satellite Data. The main data used in the development of the model are meteorological satellite data. They were obtained from the visible channel $(0.55-0.90 \mu \mathrm{m})$ of MTSAT$1 \mathrm{R}$ satellite encompassing a four-year period (2008-2011). The data can be displayed as images and there are nine images per day from 8:30 to $16: 30 \mathrm{~h}$. Each image covers the entire area of Thailand. For the convenience in image navigation and further data analysis, all images were transformed into a cylindrical projection being linear in latitude and longitude and then they were navigated by using points on the coastline as a reference. The final products were rectified images, each of which consists of a matrix of $500 \times 800$ pixels, with the pixel resolution of $3 \times 3 \mathrm{~km}^{2}$. Each pixel represents a gray level whose value varies in the range from 0 to 255 . The values of the gray level were converted into a physical quantity called the earth-atmospheric reflectivity $\left(\rho_{\mathrm{EA}}\right)$ by using a calibration table provided by a satellite data agency. Nine pixels centered at the four target ground-based PAR measurement stations were cut from each image and used to represent the earthatmospheric reflectivity of the stations. This reflectivity was used to quantify cloudiness in the modeling process. An example of a rectified image and the position of the target stations is shown in Figure 1.

As cloud is a main factor depleting solar radiation when it travels through the earth atmosphere to the ground, cloudiness is needed for the PAR modeling. In this work, cloudiness was quantified by a satellite-derived cloud index (n) introduced by Cano et al. [22] and it is expressed as

$$
n=\frac{\rho_{\mathrm{EA}}-\rho_{G}}{\rho_{\mathrm{C}}-\rho_{G}},
$$

where $\rho_{\mathrm{EA}}, \rho_{\mathrm{G}}$, and $\rho_{\mathrm{C}}$ are earth-atmospheric reflectivity, ground reflectivity, and maximum cloud reflectivity, respectively. $\rho_{\mathrm{EA}}$ was obtained from satellite data. The ground reflectivity $\left(\rho_{G}\right)$ was estimated using satellite images at noon time. Monthly composite images were generated to eliminate cloud contamination. Then, these cloud-free images were converted into ground reflectivity [23]. For the maximum cloud reflectivity, it was estimated from the maximum value of the gray level. The values of cloud index were estimated at nine pixels centered at the four target stations. The averaged value of cloud index of the nine pixels was used to represent the cloud index at these stations.

As ozone also absorbs solar radiation in the PAR wavelength interval, total ozone column data from OMI/Aura satellite were also acquired to develop the model for estimating PAR. Due to the fact that PAR is depleted by aerosols, aerosol optical depth (AOD) data retrieved from MODIS/ Terra satellite were gathered for developing the model.

2.2. Ground-Based Measurements. To formulate the semiempirical model for estimating PAR, it is necessary to acquire PAR data from measurements.

Thailand, a tropical country of Southeast Asia, is divided into four main geographical regions, namely, the mountainous northern region, the high land northeastern region, the low land central region, and the peninsular southern region. To obtain solar and atmospheric data for solar energy and atmospheric research, our laboratory has established a solar radiation monitoring station in each region. The stations are at Chiang Mai $\left(18.78^{\circ} \mathrm{N}, 98.98^{\circ} \mathrm{E}\right)$ in the northern region, Ubon Ratchathani $\left(15.25^{\circ} \mathrm{N}, 104.87^{\circ} \mathrm{E}\right)$ in the northeastern region, Nakhon Pathom $\left(13.82^{\circ} \mathrm{N}, 100.04^{\circ} \mathrm{E}\right)$ in the central region, and Songkhla $\left(7.20^{\circ} \mathrm{N}, 100.60^{\circ} \mathrm{E}\right)$ in the southern region (Figure 2 ). At each station, various instruments were installed to monitor solar radiation and atmospheric parameters, including the ground-based ultraviolet (GUV) radiometer. The radiometer has six channels in UV wavelength and one channel in PAR band (400-700 nm). It is temperaturestabilized at $40^{\circ} \mathrm{C}$. The measurements of PAR at the four stations were carried out at a frequency of one minute and averaged every hour. The radiometers at all stations are annually calibrated by simultaneous exposure with a newly calibrated radiometer supplied by the manufacturer. At the end of the study period, all radiometers were also sent back to the manufacturer for hardware check and final calibration. Considering the performance of the instruments 


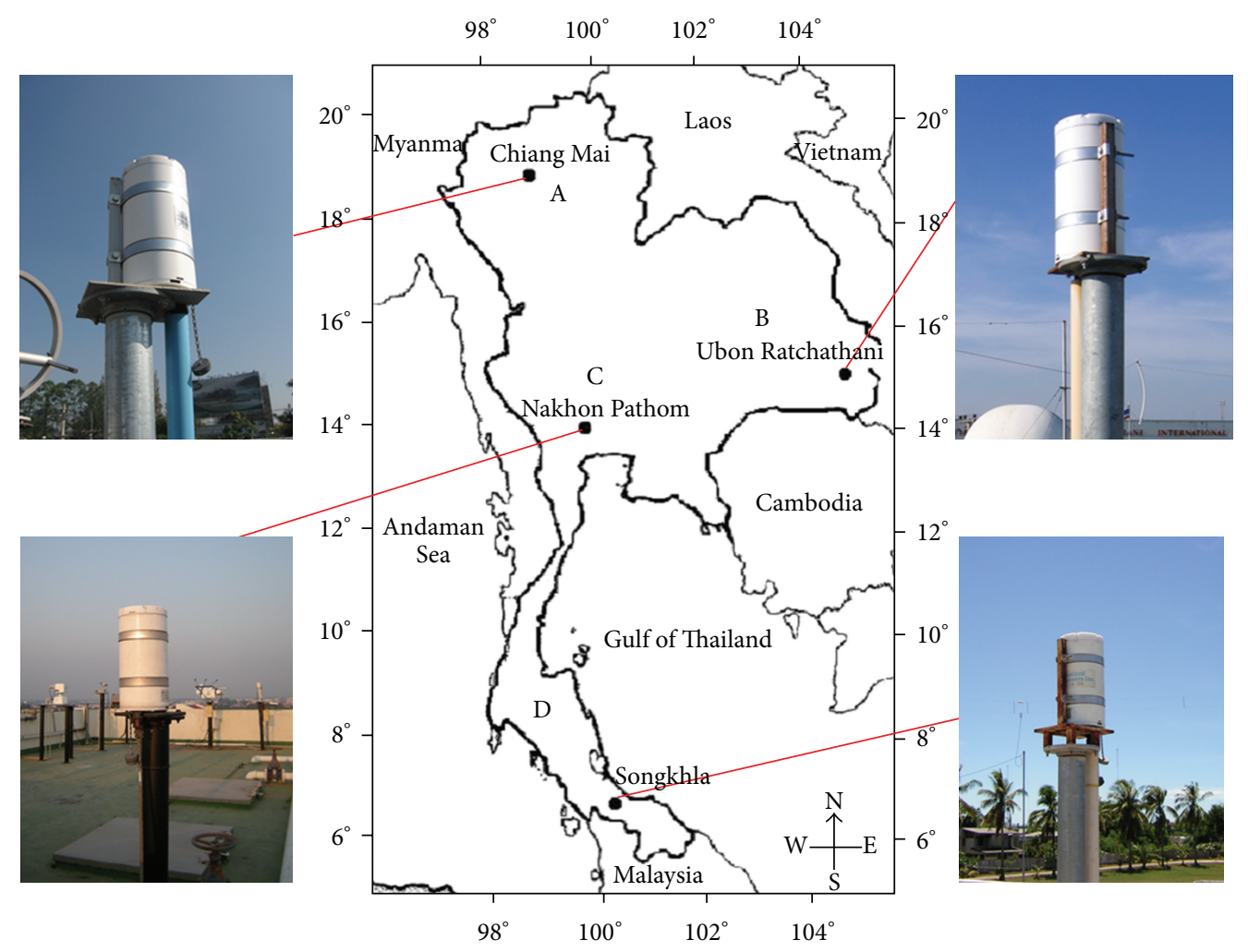

FIGURE 2: GUV radiometers and locations of the measuring stations. A, B, C, and D indicate the main regions of Thailand, namely, northern region, northeastern region, central region, and southern region, respectively.

and the calibration, the accuracy of the measurement was estimated to be less than $5 \%$.

PAR data from the four stations were separated into two data sets. The first data set was for the formulation of the model, while the second data set was for model validation. The period of the data sets from each station is shown in Table 1.

The positions and pictorial view of all instruments whose data are used in this work are shown in Figure 2. Both data from satellite and ground-based measurements were used in the modeling process presented in the next section.

\section{Results and Discussion}

The formulation of the model for estimating PAR is based on the fact that PAR is depleted by cloud, aerosol, ozone, and air molecule. In principle the effect of these atmospheric constituents can be used to formulate physically a model for PAR estimation. However, such approach is complex. To avoid the complicity, we proposed a semi-empirical model to relate PAR to the atmospheric parameters, namely, the cloud index, aerosol optical depth, total ozone column, and air mass, as follows:

$$
Q_{P}=a_{0} Q_{\mathrm{ext}} E_{0} \cos \theta_{Z} e^{-\left(a_{1} \mathrm{AOD}+a_{2} \mathrm{O}_{Z}\right) m_{a}}\left(1-a_{3} n\right),
$$

where $Q_{P}$ is global PAR $\left(\mu \mathrm{mol} \cdot \mathrm{m}^{-2} \cdot \mathrm{s}^{-1}\right), Q_{\text {ext }}$ is the extraterrestrial PAR constant $\left(2776.4 \mu \mathrm{mol} \cdot \mathrm{m}^{-2} \cdot \mathrm{s}^{-1}\right), m_{a}$ is relative optical air mass, $\theta_{Z}$ is solar zenith angle (degree), $O_{Z}$ is total ozone column (cm), AOD is aerosol optical depth $(-), n$ is cloud index (-), $E_{0}$ is eccentricity correction factor due to variation of sun-earth distance, and $a_{0}, a_{1}, a_{2}$, and $a_{3}$ are empirical constants.

To determine the empirical constants, (2) was fitted with the data of Chiang Mai, Ubon Ratchathani, Nakhon Pathom, and Songkhla by using a nonlinear multivariable regression technique [24]. The results are as follows: $a_{0}=0.854215, a_{1}=$ $0.180214, a_{2}=0.483134$, and $a_{3}=0.214929$.

To investigate its performance, the model was used to calculate PAR at the four stations, Chiang Mai, Ubon Ratchathani, Nakhon Pathom, and Songkhla, for the data periods shown in Table 1 . As these data were not involved in the formulation of the model, they were an independent data set. PAR calculated from the model and that obtained from the measurements were compared and the root mean square difference (RMSD) and mean bias difference $(\mathrm{MBD})$ relative to the mean measured PAR for different hours of the day are shown in Table 2.

From Table 2, it is noticed that the values of RMSD and $\mathrm{MBD}$ tend to increase from noon time toward the early morning and the late afternoon both for data from each station and combined data. This may be explained as follows. The main parameter affecting surface PAR is cloud which is quantified by cloud index and it is derived from imagery data obtained from MTSAT-1R satellite. The earth-atmospheric reflectivity used for calculating cloud index was derived 
TABLE 1: Schedule of data for the formulation of the model and model validation.

\begin{tabular}{lcccr}
\hline \multirow{2}{*}{ Station } & \multicolumn{2}{c}{ Position } & Formulation of the model & \multirow{2}{*}{ Model validation } \\
& Latitude & Longitude & & January-December, 2011 \\
Chiang Mai & $18.78^{\circ} \mathrm{N}$ & $98.98^{\circ} \mathrm{E}$ & January, 2008-December, 2010 & January-December, 2011 \\
Nakhon Pathom & $13.82^{\circ} \mathrm{N}$ & $100.04^{\circ} \mathrm{E}$ & January, 2008-December, 2010 & January-December, 2011 \\
Songkhla & $7.20^{\circ} \mathrm{N}$ & $100.60^{\circ} \mathrm{E}$ & January, 2008-December, 2010 & January-December, 2011 \\
Ubon Ratchathani & $15.25^{\circ} \mathrm{N}$ & $104.87^{\circ} \mathrm{E}$ & January, 2009-December, 2010 & \\
\hline
\end{tabular}

TABLE 2: Root mean square difference (RMSD) and mean bias difference (MBD) obtained from the comparison between calculated and measured hourly PAR values.

\begin{tabular}{|c|c|c|c|c|c|c|c|c|c|c|}
\hline \multirow{2}{*}{ Time } & \multicolumn{2}{|c|}{ Chiang Mai } & \multicolumn{2}{|c|}{ Ubon Ratchathani } & \multicolumn{2}{|c|}{ Nakhon Pathom } & \multicolumn{2}{|c|}{ Songkhla } & \multicolumn{2}{|c|}{ Combined data } \\
\hline & MBD (\%) & RMSD (\%) & MBD (\%) & RMSD (\%) & MBD (\%) & RMSD (\%) & MBD (\%) & RMSD (\%) & MBD (\%) & RMSD (\%) \\
\hline $8: 30$ & -4.5 & 19.4 & 0.0 & 13.4 & -8.7 & 17.0 & -10.7 & 15.0 & -5.9 & 16.1 \\
\hline $9: 30$ & -5.5 & 16.1 & -2.2 & 12.0 & -4.4 & 13.4 & -8.9 & 14.5 & -5.3 & 14.1 \\
\hline $10: 30$ & -2.6 & 12.3 & -0.3 & 8.8 & -3.1 & 9.2 & -11.6 & 14.9 & -4.2 & 11.6 \\
\hline $11: 30$ & -1.2 & 10.4 & 0.7 & 9.8 & -1.7 & 9.9 & -8.8 & 12.1 & -2.4 & 10.6 \\
\hline $12: 30$ & -1.6 & 8.2 & 3.6 & 11.3 & -2.3 & 8.6 & -11.0 & 16.1 & -2.6 & 11.2 \\
\hline $13: 30$ & -2.2 & 12.0 & 3.8 & 10.8 & -1.1 & 8.7 & -8.3 & 15.4 & -2.0 & 11.9 \\
\hline $14: 30$ & -7.5 & 18.0 & 6.5 & 18.7 & -1.3 & 11.6 & -5.7 & 13.7 & -2.6 & 15.9 \\
\hline $15: 30$ & -6.5 & 17.4 & 3.1 & 16.6 & -5.8 & 16.8 & -11.8 & 16.8 & -5.1 & 17.1 \\
\hline $16: 30$ & -16.0 & 25.2 & -12.2 & 26.1 & -15.1 & 27.4 & -22.4 & 29.8 & -16.1 & 27.2 \\
\hline All hours & -4.3 & 14.2 & 1.1 & 13.4 & -3.9 & 12.5 & -10.2 & 16.0 & -5.8 & 14.3 \\
\hline
\end{tabular}

TABLE 3: Root mean square difference (RMSD) and mean bias difference (MBD) obtained from the comparison between calculated and measured monthly average hourly PAR values.

\begin{tabular}{lcccccccccc}
\hline \multirow{2}{*}{ Time } & \multicolumn{2}{c}{ Chiang Mai } & \multicolumn{2}{c}{ Ubon Ratchathani } & \multicolumn{2}{c}{ Nakhon Pathom } & \multicolumn{3}{c}{ Songkhla } & \multicolumn{2}{c}{ Combined data } \\
& MBD (\%) & RMSD (\%) & MBD (\%) & RMSD (\%) & MBD (\%) & RMSD (\%) & MBD (\%) & RMSD (\%) & MBD (\%) & RMSD (\%) \\
\hline $8: 30$ & -13.5 & 26.9 & -0.2 & 10.1 & -7.1 & 13.6 & -12.4 & 13.9 & -8.2 & 16.8 \\
$9: 30$ & -9.0 & 14.2 & 1.2 & 9.4 & -3.5 & 8.3 & -9.8 & 12.9 & -5.6 & 11.5 \\
$10: 30$ & -8.7 & 15.8 & 1.0 & 6.3 & -2.7 & 6.7 & -12.2 & 13.2 & -6.1 & 11.4 \\
$11: 30$ & -2.3 & 5.3 & 0.6 & 7.5 & -1.3 & 6.0 & -8.9 & 10.5 & -3.2 & 7.8 \\
$12: 30$ & -2.2 & 5.6 & 1.8 & 8.4 & -0.9 & 6.5 & -10.5 & 11.9 & -3.2 & 8.7 \\
$13: 30$ & -2.2 & 6.0 & 1.8 & 9.4 & 0.0 & 5.9 & -8.0 & 9.4 & -2.5 & 7.9 \\
$14: 30$ & -5.9 & 12.9 & 8.9 & 13.3 & -1.3 & 6.3 & -5.3 & 6.6 & -1.9 & 9.6 \\
$15: 30$ & -7.3 & 11.1 & -2.4 & 20.1 & -4.4 & 11.2 & -12.3 & 12.9 & -6.7 & 13.7 \\
$16: 30$ & -18.9 & 24.2 & -11.6 & 16.6 & -15.3 & 18.8 & -22.6 & 24.9 & -17.5 & 22.3 \\
All hours & -6.6 & 12.6 & 0.8 & 10.6 & -3.0 & 8.2 & -10.4 & 12.3 & -5.1 & 11.1 \\
\hline
\end{tabular}

from radiance of the backscattered radiation by assuming that the earth-atmospheric system is a Lambertian surface. As the position of Thailand appeared at the western edge of the satellite image, non-Lambertian effect usually occurs in early morning and late afternoon, causing more errors in the calculation. Overall, RMSD and MBD for all hourly data are $14.3 \%$ and $-5.8 \%$, respectively. This relatively large discrepancy is likely due to the dominant effect of the tropical cloud whose structure and optical properties are strongly random [25], thus creating large random error of the result. In addition, the use of AOD from the MODIS/Terra satellite also contributes to this discrepancy as the AOD derived from this satellite has still relatively high uncertainty over this region [26]. To reduce such error, we examined hourly means of PAR by averaging PAR values obtained from the model over the period of one month to obtain monthly average hourly PAR. This averaged PAR represents PAR climatology which is useful for agricultural planning. The result was compared to the corresponding PAR values derived from the measurements and the RMSD and MBD are shown in Table 3.

From Table 3, it is evident that the values of RMSD and MBD for the combined data were reduced to $11.1 \%$ and $-5.1 \%$, respectively.

Van Laake and Sanchez-Azofeifa [15] proposed an algorithm to estimate PAR from data of MODIS/Terra satellite in Costa Rica and reported the average error of the estimated PAR of 5.8\%, while Liang et al. [16] used data from the same satellite and presented the relative errors in the range of 4.1$21.9 \%$, when compared with measurements in China. 
For the case of stationary satellite, Rubio et al. [18] proposed a method to derive PAR from imagery data of METEOSAT and reported the root mean square error of $29 \%$, as compared to PAR measurements in southern Spain. In our previous work [21], we developed a physical model to estimate PAR in the same area as that of this study and the root mean square difference between PAR estimated from the model and that of the measurements is $9.8 \%$. Based on the above mentioned research works, the accuracy of our proposed model is comparable to that of other models reported in literatures.

\section{Conclusion}

A semi-empirical model for estimating PAR has been developed. The model expresses PAR as an empirical function of cloud index, aerosol optical depth, total ozone column, air mass, and solar zenith angle. When tested against an independent data set for hourly PAR, the proposed model gave the values of RMSD of $14.3 \%$ and MBD of $-5.8 \%$. For the case of monthly average hourly PAR, RMSD and MBD were reduced to $11.1 \%$ and $-5.1 \%$, respectively. The proposed model provides reasonable estimation of PAR in the tropical environment of Thailand, with the accuracy comparable to that of physical models. The proposed model has an advantage in terms of its simplicity. Although the model requires cloud index, AOD, and total ozone column, the values of these parameters can be retrieved from satellites for most parts of the tropical regions. As physical parameters affecting PAR were incorporated into the model, it is expected that the model will be valid for other tropical environments.

\section{Acknowledgments}

The authors would like to thank the regional offices of the Thai Meteorological Department in the northern, northeastern, and the southern regions for their assistance in the measurements of PAR and other atmospheric parameters. The authors would like also to thank Dr. Manuel Nunez for his valuable advice.

\section{References}

[1] S. D. Prince, "A model of regional primary production for use with coarse resolution satellite data," International Journal of Remote Sensing, vol. 12, no. 6, pp. 1313-1330, 1991.

[2] S. W. Running, R. Nemani, J. M. Glassy, and P. E. Thornton, MODIS Daily Photosynthesis (PSN) and Annual Net Primary Production (NPP) Product (MOD17), Algorithm Theoretical Basis Document, University of Montana, Missoula, Mont, USA, 1999.

[3] T. Sasai, K. Ichii, Y. Yamaguchi, and R. Nemani, "Simulating terrestrial carbon fluxes using the new "biosphere model integrating eco-physiological and mechanistic approaches using satellite data" (BEAMS)," Journal of Geophysical Research, vol. 110, no. G2, 2005.

[4] M. Zhao, F. A. Heinsch, R. R. Nemani, and S. W. Running, "Improvements of the MODIS terrestrial gross and net primary production global data set," Remote Sensing of Environment, vol. 95, no. 2, pp. 164-176, 2005.
[5] S. O. Udo and T. O. Aro, "Global PAR related to global solar radiation for central Nigeria," Agricultural and Forest Meteorology, vol. 97, no. 1, pp. 21-31, 1999.

[6] C. P. Jacovides, F. S. Timvios, G. Papaioannou, D. N. Asimakopoulos, and C. M. Theofilou, "Ratio of PAR to broadband solar radiation measured in Cyprus," Agricultural and Forest Meteorology, vol. 121, no. 3-4, pp. 135-140, 2004.

[7] J. F. Escobedo, E. N. Gomes, A. P. Oliveira, and J. Soares, "Modeling hourly and daily fractions of UV, PAR and NIR to global solar radiation under various sky conditions at Botucatu, Brazil," Applied Energy, vol. 86, no. 3, pp. 299-309, 2009.

[8] I. Alados, I. Foyo-Moreno, and L. Alados-Arboledas, "Photosynthetically active radiation: measurements and modelling," Agricultural and Forest Meteorology, vol. 78, no. 1-2, pp. 121-131, 1996.

[9] X. Zhang, Y. Zhang, and Y. Zhoub, "Measuring and modelling photosynthetically active radiation in Tibet Plateau during April-October," Agricultural and Forest Meteorology, vol. 102, no. 2-3, pp. 207-212, 2000.

[10] J. A. González and J. Calbó, "Modelled and measured ratio of PAR to global radiation under cloudless skies," Agricultural and Forest Meteorology, vol. 110, no. 4, pp. 319-325, 2002.

[11] B. Hu, Y. Wang, and G. Liu, "Measurements and estimations of photosynthetically active radiation in Beijing," Atmospheric Research, vol. 85, no. 3-4, pp. 361-371, 2007.

[12] R. Li, L. Zhao, Y. Ding et al., "Monthly ratios of PAR to global solar radiation measured at northern Tibetan Plateau, China," Solar Energy, vol. 84, no. 6, pp. 964-973, 2010.

[13] T. F. Eck and D. G. Dye, "Satellite estimation of incident photosynthetically active radiation using ultraviolet reflectance," Remote Sensing of Environment, vol. 38, no. 2, pp. 135-146, 1991.

[14] P. E. Van Laake and G. A. Sanchez-Azofeifa, "Simplified atmospheric radiative transfer modelling for estimating incident PAR using MODIS atmosphere products," Remote Sensing of Environment, vol. 91, no. 1, pp. 98-113, 2004.

[15] P. E. Van Laake and G. A. Sanchez-Azofeifa, "Mapping PAR using MODIS atmosphere products," Remote Sensing of Environment, vol. 94, no. 4, pp. 554-563, 2005.

[16] S. Liang, T. Zheng, R. Liu, H. Fang, S.-C. Tsay, and S. Running, "Estimation of incident photosynthetically active radiation from Moderate Resolution Imaging Spectrometer data," Journal of Geophysical Research D, vol. 111, no. 15, Article ID D15208, 2006.

[17] R. Liu, S. Liang, H. He, J. Liu, and T. Zheng, "Mapping incident photosynthetically active radiation from MODIS data over China," Remote Sensing of Environment, vol. 112, no. 3, pp. 9981009, 2008.

[18] M. A. Rubio, G. López, J. Tovar, D. Pozo, and F. J. Batlles, “The use of satellite measurements to estimate photosynthetically active radiation," Physics and Chemistry of the Earth, vol. 30, no. 1-3, pp. 159-164, 2005.

[19] K. Schiller, "Derivation of photosynthetically available radiation from METEOSAT data in the German bight with neural nets," Ocean Dynamics, vol. 56, no. 2, pp. 79-85, 2006.

[20] T. Zheng, S. Liang, and K. Wang, "Estimation of incident photosynthetically active radiation from GOES visible imagery," Journal of Applied Meteorology and Climatology, vol. 47, no. 3, pp. 853-868, 2008.

[21] S. Janjai and R. Wattan, "Development of a model for the estimation of photosynthetically active radiation from geostationary satellite data in a tropical environment," Remote Sensing of Environment, vol. 115, no. 7, pp. 1680-1693, 2011. 
[22] D. Cano, J. M. Monget, M. Albuisson, H. Guillard, N. Regas, and L. Wald, "A method for the determination of the global solar radiation from meteorological satellite data," Solar Energy, vol. 37, no. 1, pp. 31-39, 1986.

[23] S. Janjai, W. Wanvong, and J. Laksanaboonsong, "The determination of surface albedo of Thailand using satellite data," in Proceedings of the 2nd Joint International Conference on Sustainable Energy and Environment (SEE '06), pp. 156-161, Bangkok, Thailand, 2006.

[24] G. A. F. Seber and C. J. Wild, Nonlinear Regression, John Wiley \& Sons, New York, NY, USA, 1989.

[25] M. Nunez, K. Fienberg, and C. Kuchinke, "Temporal structure of the solar radiation field in cloudy conditions: are retrievals of hourly averages from space possible?" Journal of Applied Meteorology, vol. 44, no. 1, pp. 167-178, 2005.

[26] T. Jantarach, I. Masiri, and S. Janjai, "Comparison of MODIS aerosol optical depth retrievals with ground-based measurements in the tropics," Procedia Engineering, vol. 32, pp. 392-398, 2012. 

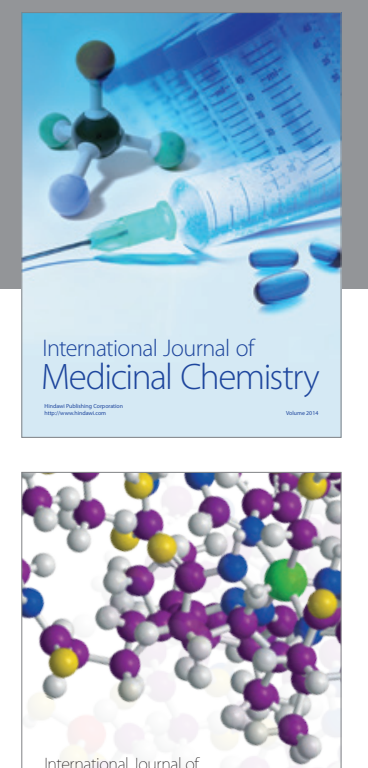

\section{Carbohydrate} Chemistry

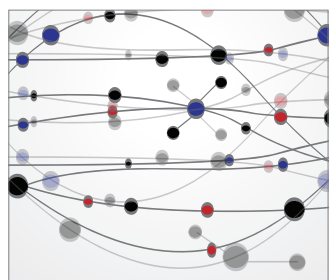

The Scientific World Journal
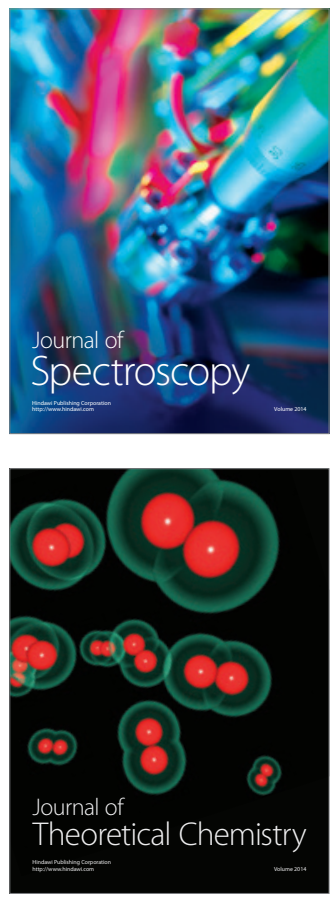
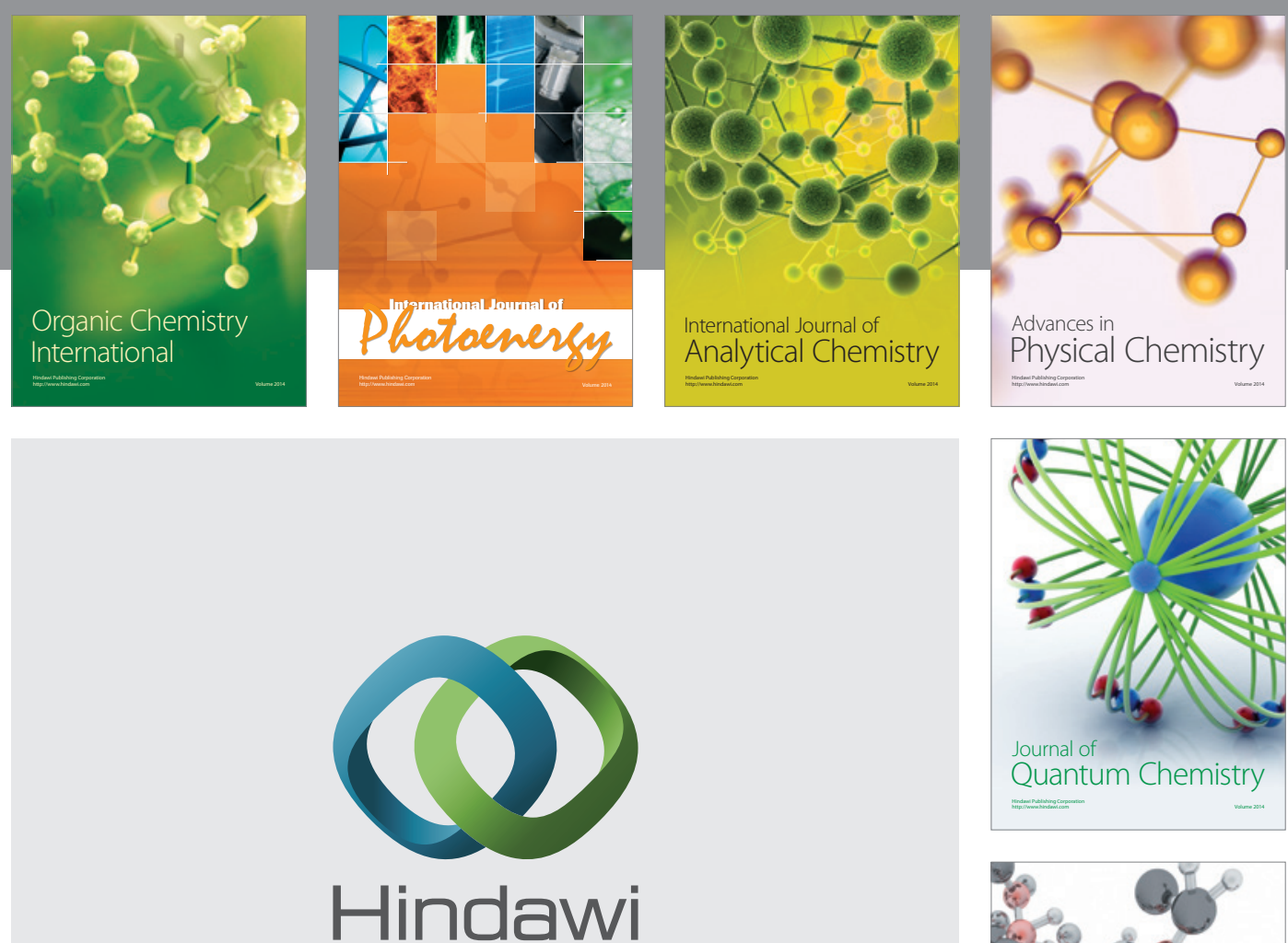

Submit your manuscripts at

http://www.hindawi.com

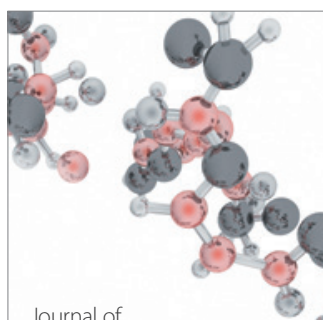

Analytical Methods

in Chemistry

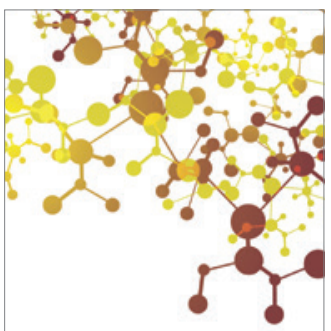

Journal of

Applied Chemistry

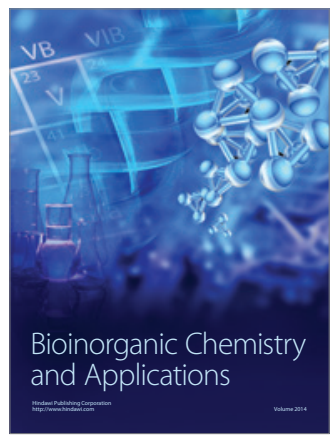

Inorganic Chemistry
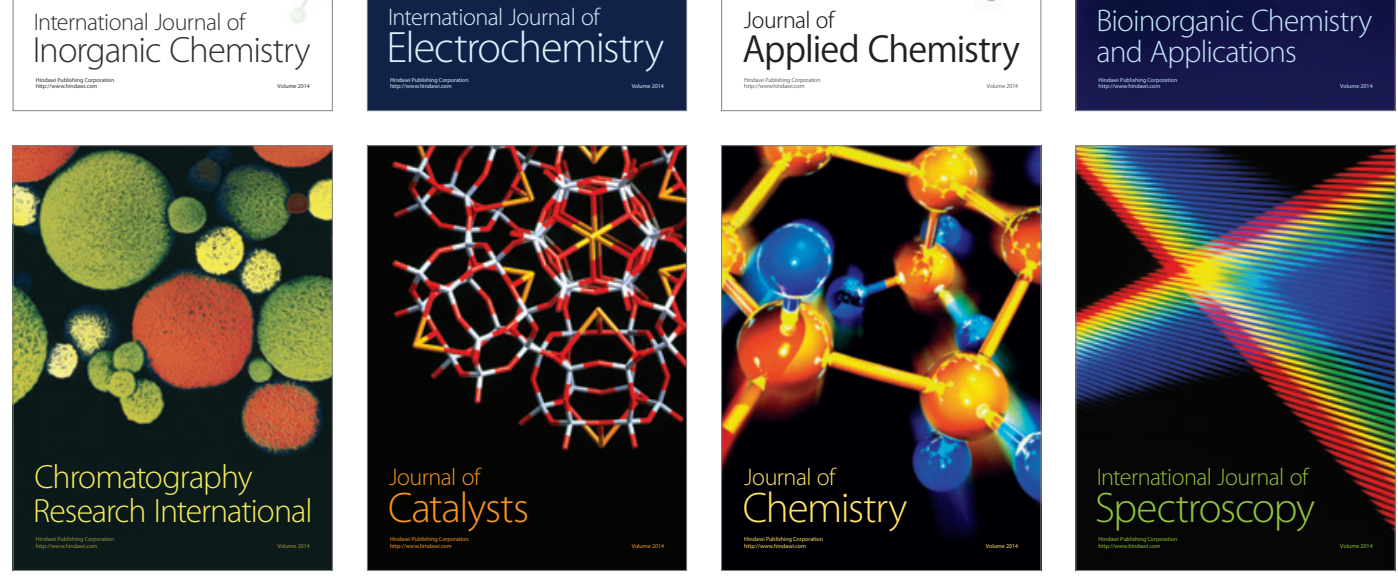